\title{
HUMANIZING THE VERTICAL CITY: THREE STRATEGIES TO BRING THE GROUND LEVEL CLOSER TO THE CLOUDS
}

\author{
ADRIÁN MARTÍNEZ MUÑOZ \\ Department of History, Theory and Architectural Composition, University of Seville, Spain
}

\begin{abstract}
The reflection on the contemporary vertical city seems to lack theoretical support that is capable of dealing with density, verticality and complexity following a model that puts the inhabitant in the center. Urban developments, mainly located in the Asian-Pacific cities, are driven by a rising real estate market that builds to speculate and not to inhabit. On the other hand, the planners, surpassed by the urgencies to which they are subjected, project environments that follow the principles of an Athens Charter, published almost 80 years ago. It is time to ask about alternatives capable of addressing the city as an organism of multiple layers and dimensions, which proposes to organize the city in height more freely, richly and more spontaneously. This paper will go over some projects, which are closer to vertical urban planning than to the building itself, which sought the radical multiplication of ground level, elevating the social and the relational away from ground level to find more human growth strategies. The actions analyzed in this text will be strategies such as the shelving of villas as an architectural structure, the location of semi-open spaces such as squares or parks distributed in height, or fragments of cities uprooted from the Earth's crust and elevated hundreds of meters. Otherwise, concepts such as community, social cohesion and urban fabric will disappear from our cities, losing the greatest value we have as a society: the collective.

Keywords: ground level, public space, vertical city, urban ground, megastructure, stacking.
\end{abstract}

\section{INTRODUCTION}

One of the earliest concepts of a vertical city was developed in 1922 by Le Corbusier, who proposed a plan where three million people would be housed in a specially designed "contemporary city". This notion of a vertical city was Le Corbusier's first systematic attempt to design an environment in which man, nature and machines could be reconciled. However, nearly 100 years later, the predominant residential building in the city today remains that of a vertically extrude tall tower. Cities continue to be filled with towers that don't address the fundamental conditions of liveability on several counts. First, at the urban scale, towers continue to be built as wall-like masses, one next to another, without the sensibility to relate to the surroundings or the street life below. Second, the apartments within these towers are often small, and interiorized, climate-controlled capsules, disconnected from the surrounding environment and with no access to outdoor spaces and amenities (Fig. 1).

The massive scale and high-density development have accelerated the shrinkage of the social life of the elderly and children, for example. The transformation of urban scale, making the city taller, bigger, and faster, increases the difficulty of social participation and segregates many people from their social context. With no place to socialize, more and more people are excluded from city life. This not only leads to great spatial changes but also destroys the memory and experience of the local residents, and destroy the organic fabric at a human scale formed over a much longer period of time.

The question remains relevant: can we design an urban environment of high intensity that is efficient, sustainable, and liveable, with the amenities, landscapes, and lifestyle choices that we enjoy on the ground? Architects must discover, and that is the aim of this paper, how 


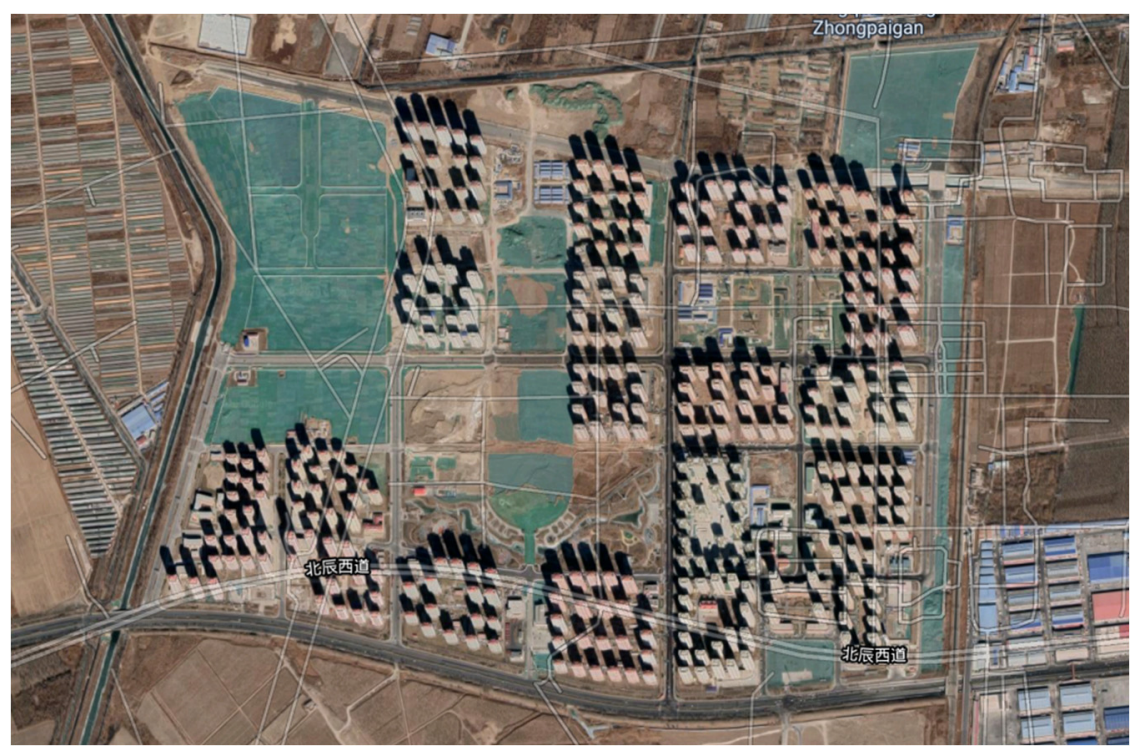

Figure 1: Vertical city today: Beichen Jixianli District, Tianjin, China. (Source: Google Earth.)

to raise the conditions of urban life on the ground floor to heights in order to humanize the vertical city of the next decades.

\section{METHODOLOGY}

In order to provide new strategies to challenge the vertical city based in modern principles and achieve models which could generate a more human city, this paper establishes a methodology which consists on tracked back some conceptual developments and ideas, made mainly from the 1960s, whose main purpose was the theoretical idea of bringing the ground level in the air as a multiplication of the real ground level.

Firstly, a deep scan of the architecture history was done, looking particularly projects and case studies of previous design proposals produced by other architects who worked with the idea of introducing a fragment of urban space radically in heights, not just a terrace or a patio in a skyscraper. The projects were chosen from different cultures and times.

Secondly, after a selection of projects mainly from the 1960s to the present, they were classified in groups sharing the same project parameters and thought through similar actions. Three groups of strategies were defined: the shelving of villas, the endless modular repetition and the cities' fragments uprooted from the earth's crust.

Thirdly, critical analysis and comparison between the projects of the same "category" was done with the target of defining a new way to rethink the vertical city. New drawings were produced to help convey some of these ideas when the bibliography wasn't complete.

It is important to note that the research of this subject is being developed in the doctoral thesis ongoing of the author.

\section{THE SHELVING OF VILLAS}

Around 1909, the publication of a realistic-looking diagram (Fig. 2) in the October issue of the satirical magazine Life, contributed, from outside the design discipline, with an idea that 
has made us reflect the most on the possibility of living at higher altitudes with conditions similar to those of the ground level. The drawing, with a concept made possible by the invention of the elevator, showed a large 84-level steel frame that contained a piece of a garden city on each floor. A slim architectural support with replaceable villas, understood as an open and ever-changing structure.

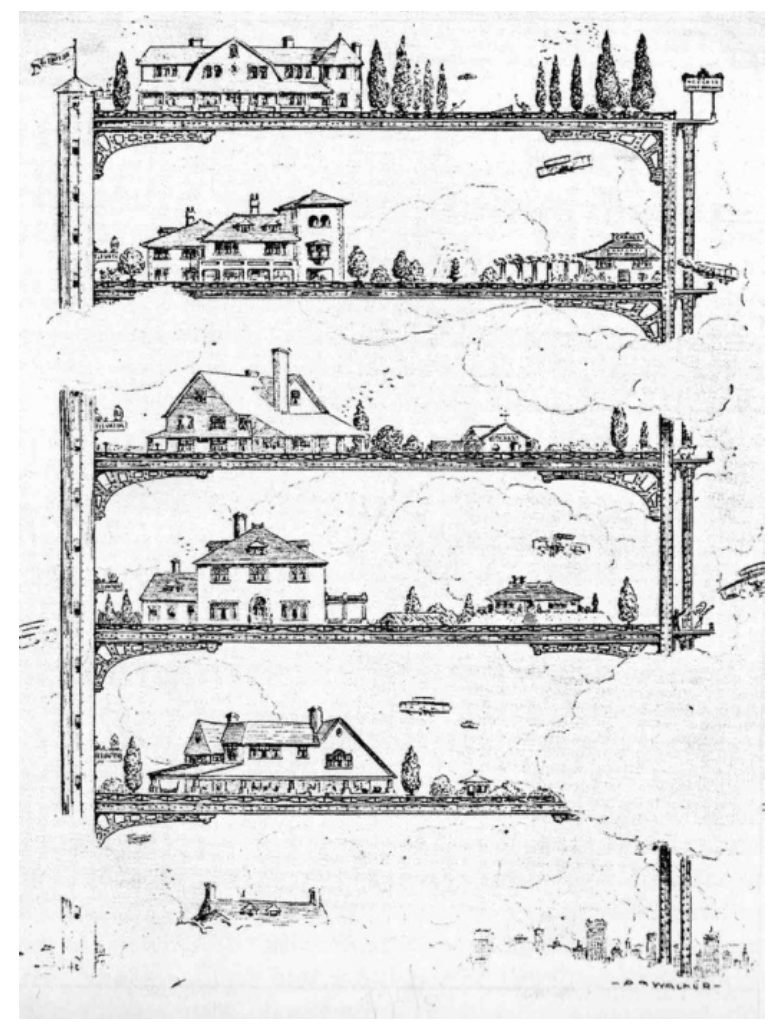

Figure 2: Theorem of 1909 [1].

While the framework of infrastructural dimensions remained untouchable, the cartoony cottages could be altered as in the city at the ground level. The robust columns, almost invisible due to the camouflage effect provided by the clouds, sheltered the elevators and stairs. Each "shelf" was separated approximately five storeys from the next, giving each landowner freedom to arrange their living volume within ample boundaries. The landscape that was reproduced on each level was idyllic, like that pertaining to life outside the city and in contact with nature. Everything in this drawing was graphed with the intention of bringing the virgin soil, until now on Earth, to the air. One perceives in this diagram the desire to enjoy the air, the light, and the views of the new vertical city that was beginning to make its way.

It was the Dutch architect Rem Koolhaas who brought this diagram to light, which he called Theorem of 1909 in his thesis Delirious New York in 1978. Possibly, Koolhaas already knew by then the concept of supporting structure [2], coined by N.J. Habraken in Des dragers en de mensen, published in Utrecht in 1962. Habraken would be well acquainted with Project “A”, Fort l'Empereur in Algiers, by Le Corbusier in 1931. This project was, according to 
Reyner Banham, the true precursor of the megastructure concept, due to its enormous length, and the differentiation between the permanent main structure and the dwellings, which were added according to the needs of the residents.

Beyond the iconographic power that the Theorem of 1909 could provide, it was a true conceptual contribution to the world of architecture that could be branded as contemporary: the strategy of multiplying a plot of the city, preserving its free spaces, gardens and orchards, several meters above the ground, inside the urban fabric of the great metropolis. A new vertical city within the city that supports and feeds it. A great three-dimensional structure, of extraordinary complexity, with a porosity of empty spaces that would make our dense cities of today more human. Above all, one wonders when contemplating this image: Where is the ground level? Are there 84 ground levels? These questions motivate this essay to begin by referring to that visionary cartoon published in an American weekly magazine.

In 1981, the SITE group (Sculpture In The Environment), following the hypotheses of N.J. Habraken and drawing from the diagram Theorem of 1909, proposed a theoretical project for a habitable tower called Highrise of Homes (Fig. 3). James Wines, founder of the SITE team, described the project as a vertical community that could satisfy the personal desire to enjoy the cultural advantages of an urban center, without sacrificing the identity of the private house and the garden space associated with the suburbs. Wines continued with the proposal of a support structure of steel and concrete, U-shaped and 8 to 10 floors high in this case, where each level could be used to develop residential programs. Wines' research did not advance conceptually with respect to the drawing published in Life magazine, but he did develop an important body of graphic work around the idea, generating perspective, elevation and plan drawings. Sketches that tried with great picturesqueness to make that first provocation of 1909 a reality. Wines' prototype came to be considered for construction in a site in Battery Park City, in New York City, but it was never built.

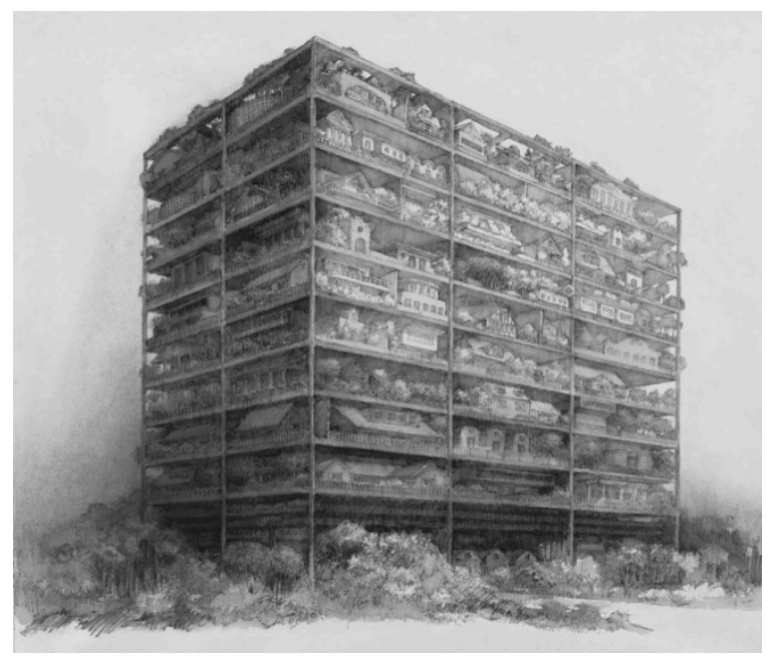

Figure 3: James Wines' Highrise of Homes, 1981 [3].

Although the work Highrise of Homes returned to the idea of multiplying the ground level, it would be some time later when a proposal with substantial changes with respect to the 1909 drawing appeared. It was the project Rustic Farms (1977) by the Dutch MVRDV office for 
the town of Waddinxveen (Fig. 4). In this project, the literal image of a "bookshelf" that was loaded with smaller buildings disappeared, giving way to the stacking of platforms as elevated open floors. The large pillar-supports that contained the communication cores were no longer designed in such a way; instead large open surfaces were stacked on top of the built volumes, a leitmotif of the Dutch office. In a way, this project lacked the conceptual power of considering the built volumes as replaceable, since they were the ones supporting the large platforms. This research, however, addressed something that its predecessors failed to do: spatial recognition of the perimeter of habitable cells at two heights. The space surrounding the house was undefined, creating an uncertain field in which multiple agreements between the inhabitants could take place. While in the Theorem of 1909 and in Wines' work the architectures placed in the great structure were designed contrasting in style with the support itself, in this project the houses had a higher level of abstraction, outlining them as prismatic volumes of two displaced levels. The relationship with the platform, which simulated the ground level, had two levels: one that reproduced life at ground level and the other corresponding with the fragment of the volume of the same dwelling lower floor. In the first case, the relationship with the elevated floor was proposed as one uses the existing ground level, that is, having it available for orchards, recreation areas, solariums, home extensions, etc. The other, a balcony-type space, corresponded to the lower floor and immediately had the following "ground level platform" above it.

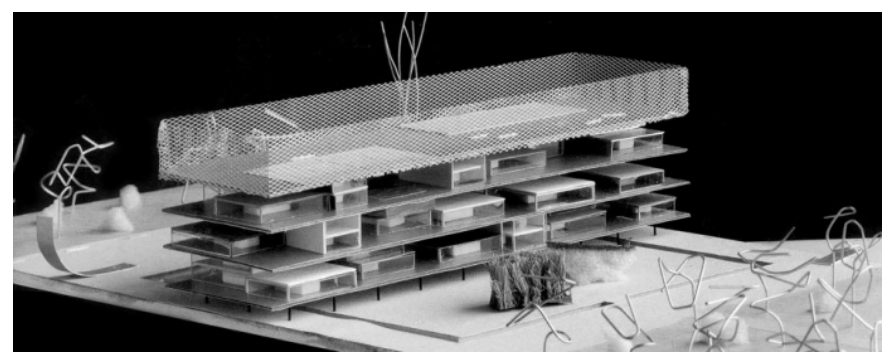

Figure 4: MVRDV, Rustic Farms, Waddinxveen, 1997 [4].

In August 2019, a brief note in The Guardian newspaper reported on the discovery of Cosmo Park: a neighborhood of 78 single-family homes located on the roof of a large shopping center in the city of Jakarta (Fig. 5). This complex, built ten years ago, was revealed thanks to photographs taken with a drone. As if it were the execution of the previously reviewed ideas, this intervention gathers a large part of the reflections on the multiplication of the ground level. Elevated ten floors and on a surface of 1.2 hectares corresponding to the roof of a shopping center, the new neighborhood is built with the same architecture as if it were located at the ground level. It does not seem to differ in any way from another located on the surface of the Earth. It is literally an exercise of reproduction of the city located a few meters below; a certain surreal urban bubble, where normal life develops at an abnormal altitude. Cosmo Park has become a sought-after luxury neighborhood for the wealthier classes due to its downtown location and great facilities, similar to those in a low-density neighborhood: from landscaped areas, private garages, community pools, sports courts, perfectly paved driveways, supermarkets and even a laundry. In this kind of futuristic dystopia there is a strange feeling of being up and down simultaneously. One lives in an environment identical to that of the street level, but on the horizon, one can see the city from 


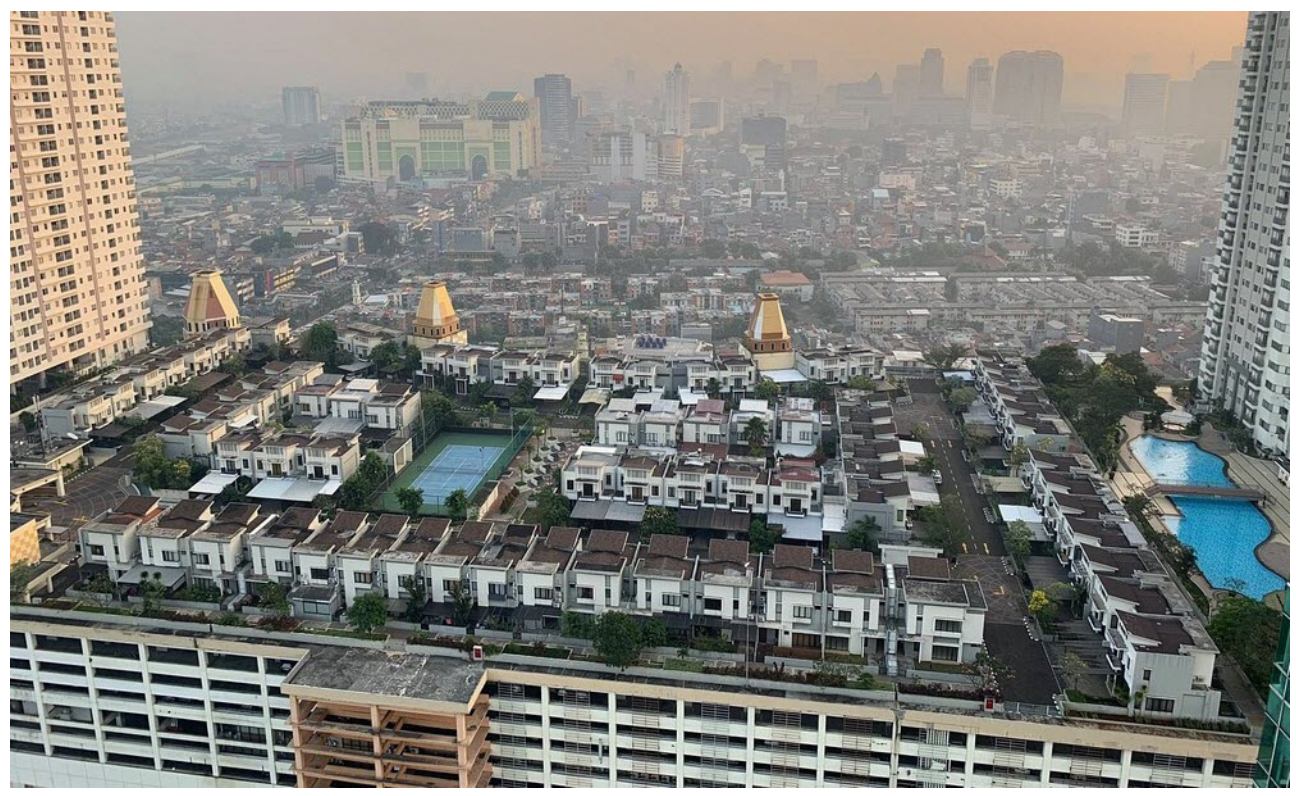

Figure 5: Cosmo Park, Jakarta [5].

above. This oasis in the center of the noisy and dense megalopolis is a suburb in the heights with the same conditions as those at the ground level.

\section{ENDLESS VERTICAL MODULAR REPETITION}

Now, it would be feasible to outline a narrative that would branch into two pairs of projects with similar actions; each of them conceived in different architectural times and cultures, but which largely share reflections. These will be the second and the third strategy that this article attempts to cover. The first pair will be composed of Tree-shaped Community (1968) by the Japanese architect Kiyonori Kikutake and the project The Coexistence Tower (1984) by the Future Systems team. In these two unbuilt towers, the action of raising the elevation of the city by repeating a module with an urban plaza contained in a built mass, became the central theme, but not as voids available to be occupied as it happened in the first strategy, but as elevated urban pores that would make verticality more human and liveable.

It seems right to point out certain similarities between the Tree-shaped Community project (1968) and The Coexistence Tower (1984) (Fig. 6). Both, in an exercise of extreme simplification, built their proposals based on the repetition of a module that responded to the most human scale in the city. As if it were the sculpture Column without end (1938) by Constantin Brancusi, these two projects approached vertical construction through the strategy of stacking identical modules with a piece of urban space inside, as a public square or park, now hundreds of meters from the original ground (Fig. 7). As in Brancusi's sculpture, the two projects seem to have neither feet nor heads and aspire to continue growing to infinity.

Danish architect Jan Gehl, very critical of the construction of the vertical city [6], expressed in several writings the need to create a city with urban quality at eye level. This appreciation interests us because it associated public space to the ground level, and this to people as something indivisible, so that the activities and actions identified with the public 


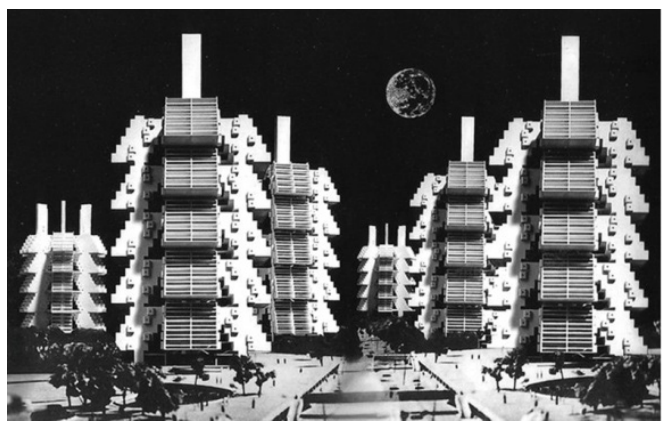

(a)

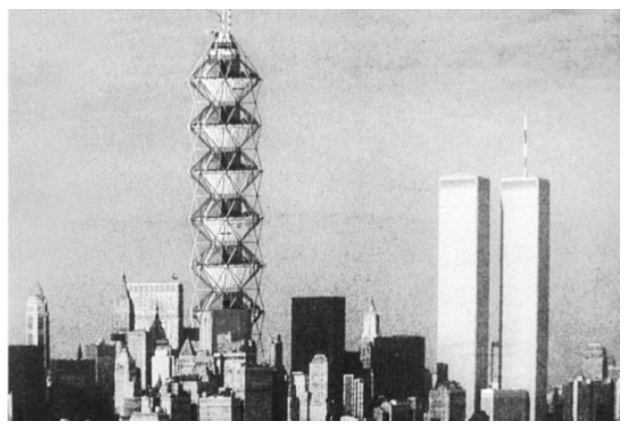

(b)

Figure 6: (a) Kikutake, Tree-shaped Community, 1968 [7]; and (b) Future Systems, The Coexistence Tower, 1984 [8].
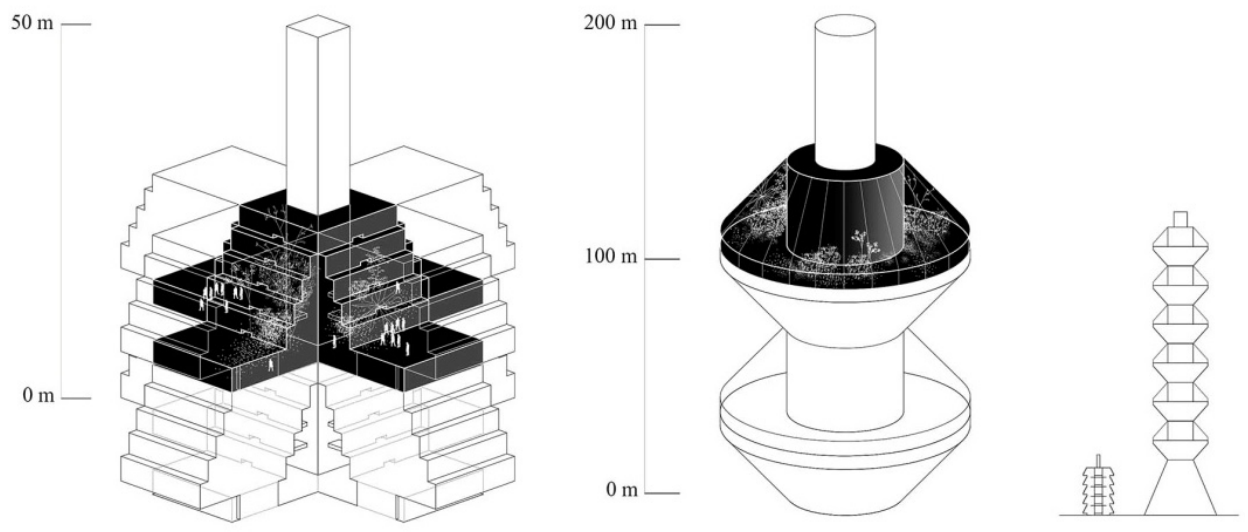

Figure 7: Identical modules stacked with a portion of urban ground inside. (Source: Diagram by the author.)

were developed: walking, standing, sitting, looking, conversing, speaking, listening and expressing oneself. In some way, this reflection indicates the need to establish elevated public urban floors so that life in the towers is fed by the urban conditions of the city. It seems that both the Kikutake project and the Future Systems project attempted to elevate that urban quality to eye level on levels equidistantly repeated across the stacked modules.

The Tree-shaped Community version from 1968 is clearly related to that idea, and in this case, motivated by the well-being of children in a residential tower. Kikutake organized its vertical community based on a five-storey module that enclosed a large atrium, like a public open space, crossed by the spine, which constituted the communication cores, and to which the access galleries to the houses overlooked (Fig. 8). The strategy was inspired by a report by Keiko Watanable that analyzed how children who lived above the fifth floor in tall buildings only watched and did not join other children who played in the park located in the city. The result was a tower where, apparently, there were no floors above the fifth. The location of that concave void open to the horizon at eye level caused the houses to be terraced 


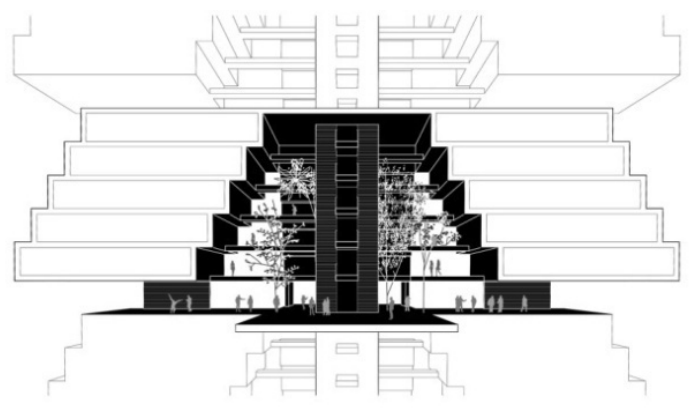

(a)

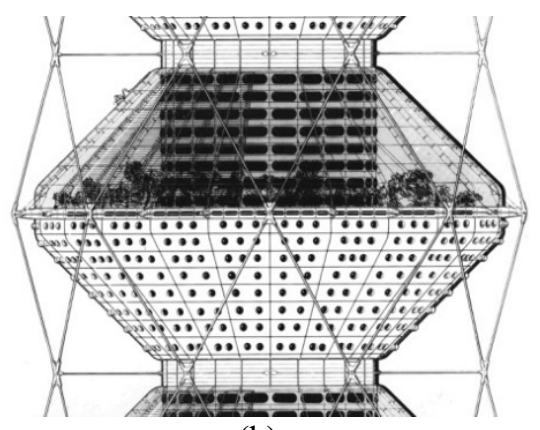

(b)

Figure 8: (a) Three dimensional section of "ground floor" Tree-shaped Community (Source: Diagram by the author); and (b) Detail of The Coexistence Tower [9].

creating clusters of five floors that gave great formal expression to the whole. The repetition of many of those towers created the illusion of a mega-forest in harmony with nature. This project contains two of the obsessions that Kikutake pursued in his work: the relationship with nature and the social relationships between people [7].

In the Kikutake project, the fragment of urban land multiplied every five levels had a cruciform plan, with each arm of the cross of approximately $15 \mathrm{~m}$, and was threaded by the core that sheltered elevators and stairs. The void was surrounded by the houses that gradually closed the section until giving way to the next module. The children would invade that communal plaza, fixing their gazes on the open landscape, which would allow them to feel high up but with no obstacles in sight. The spatial configuration of this space, opened like gills in each corner of the cross, would allow one to feel covered and protected from the weather, creating a large public volume in which to carry out the activities mentioned by Gehl.

On the other hand, almost two decades later and from a different architectural background, Jan Kaplický and David Nixon, founding partners of the Future Systems studio, gained financial support from the Graham Foundation in Chicago to explore the limits of the skyscraper. The result was the prototype Project 112: The Coexistence Tower (1984): a structure developed in collaboration with Ove Arup that reached 150 levels in a megaskyscraper that combined 672 apartments with 285,000 $\mathrm{m}^{2}$ of offices and seven elevated parks [9].

The strategy, similar to that of the Kikutake Project, although on a much larger scale, was based on the repetition of a module consisting of an inverted cone trunk of eight floors of houses, plus a cylinder of eight other floors of offices on its major base. Such a volumetric arrangement created a circular crown available as a park or public square; the space that interests us. This circular strip of urban land, multiplied seven times, was a clear example of how to raise the ground level and introduce it into a vertical building (Fig. 7). The efficiency with which this public space was included in a typology designed a priori to densify, sheds light for those who today think about how to humanize the vertical city of the future without giving up building vertically. As in the Tree-shaped Community project, the elevated urban land had a volume of air that recreated an open-air city plaza (Fig. 8). If in the Kikutake project that air was largely covered by the homes themselves, in The Coexistence Tower it was a space with a clear exterior orientation. Another empty cone trunk shaped by a warp of post-tensioned cables enclosed the new seven ground levels. 


\section{CITIES' FRAGMENTS UPROOTED FROM THE EARTH'S CRUST}

The third strategy, perhaps the most radical, that this paper tries to exemplify as multiplication and manipulation of the ground level is the one that, in an almost unnatural way, proposes to separate and elevate an imprecise fragment of earth with everything on it. The Mesa City project (1959) of the Italian architect Paolo Soleri and the project The Lifted Village (2011) (Fig. 9) of the Dutch team MVRDV could be paired within this strategy and establish a dialogue.

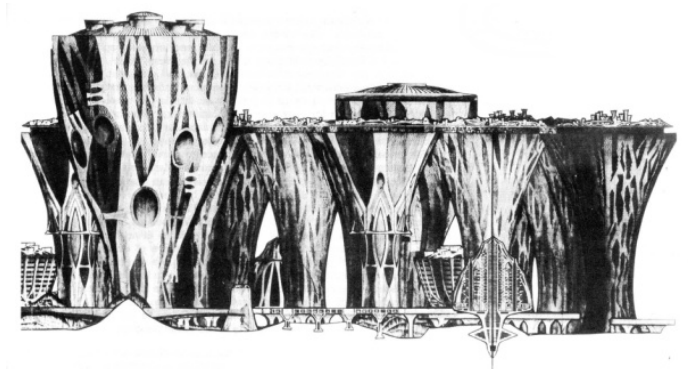

(a)

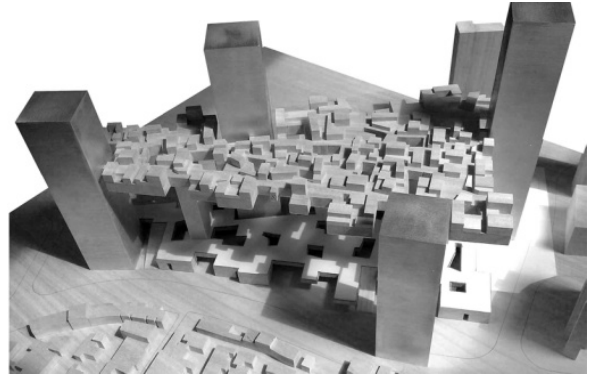

(b)

Figure 9: (a) Paolo Soleri, Mesa City, 1959 [10]; and (b) MVRDV, The Lifted Village, 2011 [12].

Among the architects considered mega-structuralists, Paolo Soleri always occupied a position difficult to classify. His reflection on how the construction of the city transformed planet Earth left a legacy of anthropomorphic architectures that had a great impact on the culture and architectural thought of the late 1950s. Soleri insistently expressed in his projects the need to concentrate and densify the human settlements to free the surface of the globe from urban sprawl [10]. Far from academic discourse, the Mesa City project was the development of the romantic idea of building a city as an accumulation of muscle mass, of energy bulges with ventricular cavities that seemed to beat. A large amount of organic matter that seemed to hatch from the earth's crust and later solidify into compact, dense, threedimensional figures. When appreciating the elevation drawings of Mesa City, it is not a glimpse of an architecture of cables, tubes or flat surfaces, but the natural expression of a city that has grown from the earth and uprooted hundreds of meters away. The project fed the fantasy of a unified city between natural geology and that manipulated by man in a perfect biological balance. An architecture like a human ecology [11].

Mesa City was designed for two million residents on approximately one hundred acres. A kind of neonature that was brought to life by the two-dimensional interaction of the different architectural organisms: dense towers in the vertical dimension and a large plateau or piece of city horizontally. All connected by a multilevel communications network that threaded the dense volumes of its arcologies. It is the trimming and elevation of a fragment of the earth's crust that we are interested in highlighting as an exemplary action of the third strategy on the multiplication of ground level. In Mesa City the dimension corresponding to the city or town on the large logs seemed the consequence of a horizontal cut at a certain height. The result was a base made up of sectioned circumferences, as if it were a cluster of bottles upside down. There the minor buildings of all kinds of programs were organized through a layout similar to that of the historic city, and the inhabitants moved in an environment that recreated the construction of society according to the Italian architect. 
On the other side of the mirror, The Lifted Village project, once again by the Dutch study MVRDV, was a contemporary case study whose way of proceeding is linked to that of Paolo Soleri, mainly with regard to the strategy of multiplying the ground level and certain visual and spatial relationships. Beyond these, they draw from different cultures and reflections, as it would happen in the previous case between Kikutake and Future Systems. The Lifted Village was the result of a competition for a prime location in the Chinese city of Shanghai in 2011. The 4.5-hectare site was in southern front of the center of Pudong, and extended towards the historic Bund, in the north. To the west of the site was the traditional YuYuan shopping area and the old town of Shanghai. The location of the project seems to offer us the keys that shaped the proposal of the Dutch team, boasting one of its maxims: the overlapping and mixing of typologies and programs. On the one hand, a group of skyscrapers responded to the dense and vertical financial district of Pudong, and on the other, a fragment of a historic city was cut out and raised $100 \mathrm{~m}$ from the ground, being hanged in the air by the group of towers.

The radicality with which the elevated "town" is captured in the images that accompany the project makes us reflect on the sensations and experiences that an inhabitant would live moving along that ground level, $100 \mathrm{~m}$ from the original land level. Undoubtedly, the fantastic provocation that this project implies leads us to reflect on its viability as an alternative architectural action to the city of towers inherited from the Modern Movement and the Athens Charter (1943). MVRDV anticipates the difficulties that this type of strategy would have: lack of sunlight under this elevated piece of city, finishing of the lower face of the rootless bark, structural complexity to support such mass in the air, and evacuation of the inhabitants in case of fire. For each one of them, they point out potential solutions: opening of large patios that introduce light into the lower city, a reflective photoluminescent system for the finishing of the inferior surface, large beams between the towers, and, finally, a structure in the form of branches between the "town" and "towers" serve as fire escape ladders, while providing secondary structural reinforcement. The latter was also intuited by Soleri in its large trunks-supports, with arms or branches that opened to cover a larger area of the supported city. Both in Mesa City and in The Lifted Village, what Jan Gehl demanded about urban quality at eye level is fulfilled, in these cases, in the elevated portion of the city.

\section{RESULTS AND DISCUSSION}

Through the comparison of the selected projects under similar conceptual actions, it has been discovered the following ideas of each strategy:

- Strategy 1. The shelving of villas: In spite of the concept is very theoretical, the present overpopulation has demonstrated this idea could be interesting to explore in order to reuse a series of marginal urban space, as the Cosmo Park case do. The flexibility offered by this concept would be promoted to change the capability of a tower considering that his purpose is to be adaptable to the necessity of the city. Also, the idea of situating a ground urban level ready to be altered with similar conditions to the real ground floor would be a great value to investors. Besides a new relationship between the structure and the built mass, creating a space without specific use and with a lot of possibilities.

- Strategy 2. The endless vertical modular repetition: The great inconvenience of living in a very high tower disconnected many meters from the ground of the city is challenged in the Kikutake and Future Systems projects. Both projects, the idea of building in height is used through the addition of a module of several floors with a fragment of urban land inside. This idea could be very interesting to make life in the towers more bearable, for example for children, because they will have the sensation of living close to an urban square or park. 
- Strategy 3. Cities' fragments uprooted from the earth's crust: Mesa City project (1959) by the Italian architect Paolo Soleri and The Lifted Village project (2011) by the Dutch team MVRDV reflected on how to uproot a fragment of the earth's crust and elevate it, almost as in science fiction. This provocative idea could contribute interesting possibilities to displace urban structures to the height. Here it would be a problem the evacuation of inhabitants because the fragment of land in the air is bigger than the other strategies. In the Lifted Village's project, we can see how this is one of the most fragile decision.

All projects commented would come to answer the investigations of the environmental psychologist Robert Gifford, a professor at the University of Vitoria in Canada. Gifford, in his article The Consequences of Living in High-Rise Buildings (2007), analyzed from various points of view the side effects of living in residential towers. The article began by asking: "Are residential towers good or bad for people?" [13]. The methodology used to carry out the report was based on personal interviews with the inhabitants and on direct observations through case studies, always with the focus on the search for difficulties related to living in vertical buildings. Among the most studied problems were fear, dissatisfaction, stress, behavioral changes, suicide, lack of social relationship, lack of solidarity and developmental problems in children.

In a fragment of the text, Gifford analyzed the behavior and development of children living in high-rise residential typologies with respect to those who do so close to the street level. The author's conclusion from the study speaks of a child growing up inside a tower suffering from misbehavior and continuous tantrums, in addition to disorders such as primary nocturnal enuresis. The activity that best stages this lack is play. A daily action that we usually carry out in streets and squares around us, but in these cases, families who live in towers do not feel safe by allowing their children to play on the street, separated vertically by hundreds of meters from their home. Therefore, children are pushed to grow inside the cell, using their time for play in solitary entertainments that not only impede their motor development, but also harm their future personality. Gifford, however, pointed out that these behaviours would improve if the residential towers had green and play areas similar to the city below.

In the light of the results, the strategies analyzed show different alternatives about how to raise the conditions of urban life on the ground floor to heights. If we establish a comparison between the projects commented and the modern urbanism of identical towers one next to another in an infinite grid, we will understand the profits for people's life, generating a city model more human.

Finally, several prototypes of residential megastructures are being built facing with this purpose in the city of Singapore. This city is a pioneer in this type of project, among which is The Pinnacle Duxton, built by ARC + RSP Architects in 2009 (Fig. 10). A vertical complex of 1,848 houses and 50 storeys high that dreams of literally bringing the street and the Plaza to the clouds, producing elevations of urban strata several meters from the Earth's mass to create a multi-ground zero city. A kind of spatial illusion built on the basis of two horizontal "trays" that cross the towers, which contain: gardens for children's games, areas for barbecues, solariums and areas equipped for gymnastics.

\section{CONCLUSION}

According to current United Nations (ONU) projections, by the year 2050 the world population will increase from 7.6 billion to 9.7 billion and close to $66 \%$ of this population will live in cities, declaring the age of the vertical city. So, what if it was not possible to reject the construction of the city vertically? [15]. 


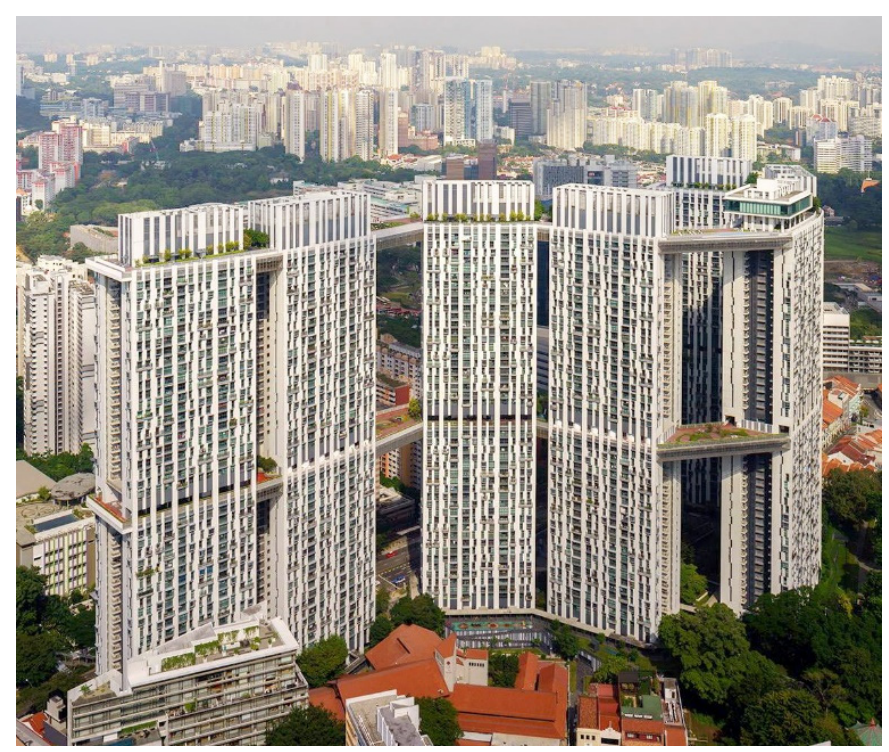

Figure 10: ARC+RSP architects, The Pinnacle Duxton, Singapore, 2009 [14].

The three strategies mentioned above on the multiplication of a piece of city land can help start a new period of reflection on how we should face the construction of the vertical city of the future. While the cities today already face the phenomenon of verticalism, they do so based on simple modern planning according to the canons of ventilation, lighting and vegetation. The case studies discussed in this text could provide avenues to explore to transfer life in the ground of the city to the heights. It seems appropriate to return to some of those architectural actions that fostered the transfer of the most collective plan in the city, the ground level, closer to the clouds.

\section{ACKNOWLEDGEMENTS}

The author would like to recognize the generous help of VI Plan Propio de Investigación y Transferencia 2020 of the University of Seville. Also, this project is funded in part by the Education Ministry of Spain with a FPU scholarship, which I acknowledge with great thanks.

\section{REFERENCES}

[1] Koolhaas, R., Delirio de Nueva York, Gustavo Gili: Barcelona, p. 82, 2004.

[2] Habraken, N.J., Soportes: Una alternativa al alojamiento de masas, Alberto Corazón editor: Madrid, 1975.

[3] Wines, J., Highrise of Homes, project (exterior perspective), Museum of Modern Art, New York, 2nd floor, 216, no. 581.1981.

[4] MVRDV 1991-1997, El Croquis, no. 86, pp. 152-215, 1997.

[5] Lamb, K., Suburb in the sky: How Jakartans built an entire village on top of a mall. Photo by S. Bahar. The Guardian, Cities, Aug. 2019.

[6] Gehl, J., La humanización del espacio urbano: La vida social entre los edificios, Reverté: Barcelona, 2006.

[7] Koolhaas, R., Project Japan: Metabolism Talks..., Taschen: Colonia, 2011. 
[8] Ábalos \& Herreros archive, 1978-2006 (ref. ARCH273090), Canadian Centre for Architecture: Montréal.

[9] Pawley, M., Future Systems: The Story of Tomorrow, Phaidon: London, 1993.

[10] Banham, R., Megaestruturas: Futuro urbano del pasado reciente, Gustavo Gili: Barcelona, 1978.

[11] Iolanda, A., Soleri: Architecture as Human Ecology, Monacelli Press: New York, 2003.

[12] MVRDV, The lifted village. www.mvrdv.nl/projects/220/the-lifted-village.

[13] Gifford, R., The consequences of living in high-rise buildings. Architectural Science Review, 50(1), 2007.

[14] ARC Studio, Architecture + Urbanism. http://arcstudio.com.sg/.

[15] Martínez, A., De la torre residencial a la megaestructura en el aire. Una reflexión crítica sobre la ciudad vertical contemporánea. RITA, 13, 2020.

DOI: $10.24192 / 2386-7027(2020)(v 13)(02)$. 